\title{
FOUCAULT E OS DISCURSOS SOBRE "DROGAS": DA DEFINIÇÃO DO OBJETO À INCORPORAÇÃO DOS DESVIOS
}

\begin{abstract}
Andrew Müller Reed ${ }^{1}$
RESUMO: Trata-se de um exercício reflexivo sobre o uso de "drogas" na atualidade, tendo como base o arcabouço teórico desenvolvido por Foucault em sua análise sobre a sexualidade. A hipótese subjacente é de que é possível identificar nas sociedades modernas um processo de colocação das "drogas" em discurso, definindo-a como um objeto de saber a ser conhecido e controlado. Busca-se portanto analisar as diferentes formações discursivas sobre as "drogas" e suas representações nos campos estabelecidas do poder, culminando em uma reflexão sobre as consequencias desse processo na elaboração individual do uso de "drogas" e a incorporação subjetiva dos desvios.
\end{abstract}

PALAVRAS-CHAVE: Drogas, Desvio, Subjetividade

Para citar este artigo:

REED, Andrew; Foucault e o discurso sobre "drogas": Da definição do objeto à incorporação dos desvios. In: Revista Intratextos, 2013, vol 4, no1, p. 162-179. DOI: 10.12957/intratextos.2013.8459

\footnotetext{
${ }^{1}$ Mestrando do Programa de Pós-Graduação em Ciências Sociais da Universidade do Estado do Rio de Janeiro. Bolsista Capes. Email: andmulreed@gmail.com
} 


\section{Introdução: ruptura, vontade de saber e discursividade}

Este trabalho tem como objetivo refletir sobre o atual tema das "drogas" a partir de uma analogia com o estudo desenvolvido por Foucault sobre a sexualidade $(1988)^{2}$. Foucault principia A História da Sexualidade com um esforço de desconstrução do pressuposto teórico da Psicologia e Psicanálise modernas, segundo o qual a sexualidade na época clássica, aproximadamente até o início do século XVII, era livremente exercida e tolerada, quando passa a ser fortemente reprimida. Ela então é modelada no casal legítimo e procriador da família conjugal, e, fora destes limites, proibida, encerrada, calada, condenada ao desparecimento, afirmada inexistente. Tal "hipótese repressiva" baseia-se na idéia de que a ordem de desenvolvimento do capitalismo na sociedade burguesa torna incompatível o sexo livre com o trabalho. O único lugar da sexualidade reconhecido é o quarto dos pais, em sua função reprodutiva e util: tudo o mais é fadado a encobrir-se, coberto de decoro e decência em gestos e palavras, proibido até em sua menor menção. As sexualidades ilegítimas são tachadas de anormais e relegadas (além de exploradas economicamente por) às casas de prostituição e de saúde: putas, clientes, cafetões, o psiquiatra e a paciente histérica.

Pois que, Foucault afirma, o discurso da repressão parece ser ele mesmo coberto por uma aura de transgressão, como se o próprio falar de sexo e de sua proibição estivesse fora do alcance da lei. Como se fosse em si mesmo um ato revolucionário que promete um futuro libertador (e prazeroso). Isso explicaria toda a gama de sutilezas encontradas ao tratar do sexo em termos de repressão. Na solenidade das falas, na pose, no tom de voz, cheios de consciência da subversão. Como uma pregação, denunciando hipocrisias, revelando uma verdade, prometendo uma felicidade vindoura: "o enunciado da opressão e a forma de pregação referem-se mutuamente; reforçam-se reciprocamente". (FOUCAULT, 1988, p. 13).

Não seria o caso de negar a tese e afirmar seu inverso simétrico, ou seja, que o sexo não é reprimido, mas sim de analisar os interesses políticos que sustentam toda uma economia global dos discursos sobre o sexo nas sociedades modernas a partir do século XVII, dentro da qual a hipótese repressiva se localiza. O termo "político" é aqui entendido não apenas no sentido do campo de atuação política oficial, legitimado pelas instituições

\footnotetext{
${ }^{2}$ Uma versão preliminar do artigo foi apresentada em 2012 como trabalho final do curso de Teoria Social ministrado pelo professor Carlos Eduardo Rebello.
} 
nacionais, mas, principalmente, uma idéia de poder que permeia toda a sociedade e alcança o comportamento individual através de formas discursivas; que penetra o cotidiano através de diversos dispositivos, mecanismos e técnicas.

É ao focar sua análise sobre a sexualidade humana nos discursos que a formam que o autor traz sua contribuição fundamental, inserindo o tema em nova perspectiva teórica que influenciou o campo das ciências humanas a partir da década de 1970. Em As Palavras e as Coisas (2000a), Foucault propõe uma arqueologia da epistème ocidental, ao identificar na passagem da idade clássica para a moderna uma mudança significativa na "ordem do saber". Trata-se de refletir sobre as condições de possibilidade da construção de um novo tipo de conhecimento. O novo conceito universal de "homem" o define como "figura do saber", como sujeito cognoscente. Ao mesmo tempo, por outro lado, esse humanismo coloca o homem como o objeto empírico do saber. É quando se dá a ascenção e o estabelecimeno Ciências Humanas. Novo "homem": sujeito e objeto do conhecimento. Contudo, ressalta Foucault, o conhecimento, o saber, a realidade, as verdades, não estão na materialidade das coisas, e sim nas palavras, na ordem do discurso que damos às coisas, no intelecto humano. Dessa forma, é possível interpretar as categorias através das quais supostamente se pode representar a realidade das coisas como processos formados discursivamente. Tratam-se de classificações feitas a partir da uma ordem de prioridades, frutos de uma vontade de saber que persegue a possibilidade de se falar qualquer coisa sobre qualquer objeto, cuja essência é discursivamente elaborada.

Esse enfoque teórico permite evidenciar o conflito inerente ao estabelecimento do que é o conhecimento. Deixa à mostra os jogos de poder na vida social, em seu caráter discursivo de definição da realidade. Ao fazer tal deslocamento, Foucault questiona a idéia de Totalidade, e sua História passa a ser uma história dos saberes, com a atenção voltada para fenômenos de ruptura, de descontinuidade. Em A Arqueologia do Saber, o autor indica a necessidade de libertação deste "jogo de noções" que tratam com uma naturalidade irrefletida as idéiais de totalidade e continuidade, pressupostos teóricos tomados como dados, através dos quais se organizam os grandes tipos discursivos: a ciência, a literatura, a filosofia, a religião (FOUCAULT, 2000b). Essa suposta continuidade histórica observada nos discursos poderosos é correlata indispensável à função fundadora do sujeito, do homem enquanto "sujeito do saber", ocorrida nesta passagem que marca tão profundamente a sociedade contemporânea. 
Mas ela é aqui posta à prova. Dessa maneira, a unidade dos objetos é contestada, já que cada discurso constitui seu próprio objeto e o elabora até transformá-lo inteiramente como seria o caso da sexualidade, e, quero demonstrar, das "drogas". O objeto não pré-existe a si mesmo: só existe sob as condições positivas de um feixe complexo de relações de poder e práticas que sistematicamente o permitem surgir e o modelam. Portanto, o primeiro papel do poder é enunciar as verdades e, por consequência, as mentiras; por trás da noção de discursividade, além de estabelecer o que vai ser dito, estabelece-se o que não vai ser dito, o que é digno de ser sabido. Sendo as regras políticas, de formação das categorias, dadas nos discursos, é a eles que se deve voltar a atenção.

Assim, tendo como pano-de-fundo a sociedade permeada por relações de poder e interesses, e a "vontade de saber" do homem enquanto sujeito, que é suporte e instrumento das produções discursivas, o objetivo de Foucault ao analisar a sexualidade não é denunciar uma repressão ao sexo na modernidade, mas determinar o "fato discursivo global", ou seja, as razões de ser e o funcionamento do regime poder - saber - prazer que sustenta o discurso sobre a sexualidade humana, levando em conta "o próprio fato de se falar de sexo, quem fala, os lugares e os pontos de vista de que se fala, as instituições que incitam a fazê-lo" (FOUCAULT, 1988, p. 16). Nesse sentido, a hipótese repressiva e todos seus elementos negativos de proibição, censura e recusa ao sexo são encarados como parte integrante de um mecanismo funcional na formação discursiva das produções de poder e de saber, onde a colocação do sexo em discurso parece, desde o século XVI, não diminuir ou ser reprimida, mas sim disseminar-se e multiplicar-se insistentemente, constituindo-se em uma ciência da sexualidade.

Minha hipótese é de que é possível construir argumento semelhante, neste caso, com relação à droga, tomada em seu sentido ampliado, e seu uso pelo homem. O objetivo portanto não é denunciar uma repressão ao uso de "drogas" na modernidade, mas atentar para o funcionamento de um regime de saber e de poder que sustenta um discurso específico sobre o uso de "drogas", a própria definição do objeto-droga, tendo em vista o fato de se falar sobre "drogas", quem fala, os pontos-de-vista de que se fala, as instituições que incitam a fazê-lo. Tendo como base o arcabouço teórico definido por Foucault, seria possível identificar nas sociedades burguesas múltiplas formações discursivas sobre "drogas", a partir do séc. XVIII, que antes de determinarem sua extinção, incitam sua formulação em discursos ordenados. 
É preciso salientar que há importantes diferenças e especificidades entre os temas da droga e da sexualidade. Aqui, "droga" é entendida como um objeto discursivo mas também objeto de fato, ou seja, uma substância, um artifício, um artefato separado do homem e externo a ele; já o sexo é tratado como uma ação humana que se basta no corpo (eventualmente corpos). Ao mesmo tempo, as "drogas" entram nos corpos, misturam-se a eles, e seu uso é também ação humana. Por outro lado, o sexo pode munir-se de objetos, artefatos auxiliares, e ser ele próprio objeto de outras sexualidades. Em ambos os casos, mantém-se a injunção poder-prazer. O uso de "drogas" ilícitas como um fenômeno de massa é um movimento mais tardio e moderno, assimilado à industrialização, o urbanismo e a cultura de massas, cuja domesticação discursiva teve seu apogeu talvez em período posterior ao processo observado por Foucault com a sexualidade. Não que não se usassem drogas antes do séc. XVIII, desde o uso ritual e social do vinho nas festas de Baco e nos banquetes na Grécia Antiga (GUARINELLO, 2008), na matriz cultural ocidental, e principalmente os usos de sociedades não-ocidentais que tradicionalmente administravam chás, bebidas, cultivavam ervas, plantas, cactus, cogumelos, raízes, tabaco, considerados sagrados e utilizados religiosamente em caráter ritual; mas que a categoria "droga" ainda não era dada a essas coisas, pois o surgimento e talvez o ápice da colocação da "droga" em discurso tenha se dado a partir de contexto histórico relativamente mais recente, notadamente a partir da primeira metade do século XX. Assim, será necessária certa licença para adaptar os exemplos específicos de discursividade utilizados por Foucault, pois este não é um trabalho de pesquisa histórico exaustivo. O termo "drogas" será usado de forma abrangente e não tratará apenas das chamadas drogas ilícitas, como utilizado no jargão jurídico, administrativo estatal e mesmo no senso comum. Certa confusão de denominação só mostra o quanto a definição do objeto é atravessada por discursos contraditórios e definidores.

\section{Análise dos discursos nos campos estabelecidos do poder}

Seguirei expondo a estrutura argumentativa e analítica de Foucault sobre a sexualidade, ampliando o debate para o campo das "drogas". Pois que, com relação ao sexo e às "drogas", portanto, teria havido uma redução no nível da linguagem, como se fosse necessário emudecer os discursos, extinguir as palavras que os professam, silenciar sobre o tema, para dominá-lo no plano real. Entretanto, o que se observa é o contrário. É evidente que o vocabulário autorizado foi delimitado. Novas codificações, retóricas e metáforas foram 
definidas. Locais, contextos e relações específicas permitem que se toque no assunto, enquanto de outro lado criam-se regiões de silêncio, vigilância, cuidado, tato e discrição. Assim como sobre sexo, não se pode falar sobre droga livremente, em qualquer lugar ou contexto. Não estamos falando tanto, neste momento, dos discursos desviantes, possívelmente multiplicados como reação às novas regras, mas daqueles dentro do próprio campo do exercício do poder. Conceitos totalizantes, nomes científicos e apelidos pejorativos são utilizados para fazer refeferência ao sexo e às "drogas", isso quando ela não se dá através de adjetivos, sinônimos ou metonímias, sugestões subentendidas, gestos teatralizados, olhares reveladores. Tampouco pode-se enunciar sobre o assunto fora de relações sociais específicas, fora de contextos e locais adequados e legítimos, de regiões estabelecidas do campo do poder, sobre as quais vamos nos focar.

No discurso moral religioso, como lembra Foucault, a confissão torna-se central como um dos sete sacramentos da igreja católica a partir do Concílio de Trento, no movimento conhecido como Contra-Reforma. A religião passa a focar-se nos pecados da carne, alcançando terrenos para além do ato em si: o exame individual de consciência é incentivado até o limite para buscar a penitência nos mínimos desejos, vontades e pensamentos. E, a partir de meados do século XX, o uso de "drogas" (ilegais) passa a ser, assim como o sexo (fora do casal legítimo), enquadrada como vício, o oposto da virtude, a recorrência do pecado.

No pentecostalismo contemporâneo, os testemunhos são relatos emocionais de histórias de vida pormenorizados: ex-viciados e ex-traficantes detalham os absurdos de uma época em que eram dominados pelo Mal. Cenas de descarrego se produzem para a salvação dos perdidos. É preciso não se deixar cair em tentação: a droga é o diabo, resistir a ela é a verdadeira provação. O demônio na pessoa: o dependente é um "perdido", não controla seus desejos, sua consciência. Está dominado. Ao indivíduo é colocada a tarefa de elaborar em discurso tudo que tenha o mínimo relacionamento com o tema, a menor menção, qualquer sombra de desejo.

Na literatura, o mesmo processo se observa. É preciso detalhar tudo: não apenas o ato em si, mas os olhares, os pensamentos, devaneios. Como nos ilustra Foucault, Marques de Sade é o exemplar da literatura erótica escandalosa, assim como o autor anônimo de $M y$ Secret Life, cuja narrativa descreve uma vida dedicada à atividade sexual. No mesmo sentido, Thomas De Quincey, em seu auto-biográfico Confissões de um Comedor de Ópio, publicado 
originalmente em 1821, descreve em detalhes seu cotidiano de experiências com a droga e a influência dos efeitos opiáceos em sua mente. A narrativa relata a evolução de seu vício, até o momento em que finalmente se resigna em sua dependência. Assim como o anônimo sexômano, que justifica suas estranhas práticas pelo fato de não ser o único a fazê-las, De Quincey aponta para o grande número de "comedores de ópio" presentes nas mais diversas classes sociais da Inglaterra no século XIX. O único fator que diferenciava ambos autores de todos os anteriores é o de que houvessem relatado minunciosamente suas práticas exóticas.

Diz-se que o estilo corrido de De Quincey, sem lógica bruta, com certa liberdade de associação, é fruto do efeito do ópio enquanto escrevia. Inspirado nele, Charles Baudelaire escreve, em 1860, Os Paraísos Artificiais, ópio e haxixe, com minunciosas observações e relatos das sensações provocados pela ingestão de substâncias psicoativas, a partir de seu próprio uso e da convivência no "Club dês Hashishins", grupo de poetas, pintores e jovens intelectuais franceses que experimentavam a produção artística sob efeito de tais substâncias, além de uma ode ao vinho como necessidade básica do intelecto do homem. Já em 1954 Aldous Huxley segue a linha das explorações literárias sobre o tema ao escrever As Portas da Percepção, onde, sob efeito, descreve em pormenores suas experiências de expansão da percepção e alteração de consciência com o uso de mescalina, substância extraída do Peyote, cactus originário do México utilizado ritualmente por xamãs. "É preciso, nas narrativas, o maior e o mais extenso detalhamento", diz Sade (FOUCAULT, 1988, p. 24).

Esses autores podem ser vistos menos como bravos rebeldes de um moralismo silenciador, do que representantes de uma injunção histórica de falar de "drogas", do sexo. Esse incitamento a falar de si já estava delineado em alguma medida na pastoral cristã e no discurso moral religioso, através de uma técnica que procura produzir efeitos específicos sobre o desejo do indivíduo. A confissão religiosa, argumenta Foucault, expande-se para outros campos e se torna um discurso central de verdade sobre "si mesmo". Na confissão, o sujeito que fala coincide com o sujeito do enunciado. Ao mesmo tempo, é um ritual que ocorre em uma relação de poder, mesmo que a presença da instância que requer a confissão seja virtual. Ela realiza, assim, a sujeição dos homens, em seus dois sentidos: sua constituição enquanto sujeitos individuais, dotados de uma subjetividade; ao mesmo tempo que assujeitados, subordinados. Enquanto na idade média o indivíduo era concebido pela manifestação de vínculo a outros, como família, senhorio ou reino, na passagem para a modernidade o indivíduo "passou a ser autenticado pelo discurso de verdade que era capaz de 
(ou obrigado a) ter sobre si mesmo. A confissão da verdade se inscreveu no cerne dos procedimentos de individualização" (FOUCAULT, 1988, p. 67). O indivíduo passa a ter que discursar sempre sobre seus pensamentos e sentimentos, sobre o que lhe dá prazer e dor.

Tal processo de detalhamento e produção de saberes é reforçado por outros mecanismos discursivos institucionais, como o chamado "interesse público" sobre as “drogas”, um discurso essencial para o exercício de poder, uma incitação política, econômica, técnica, a falar de droga, notadamente a partir do século XX. É o discurso não tanto da moral, mas da racionalidade sobre a droga, "sob forma de análises, de contabilidade, de classificação e de especificação, através de pesquisas quantitativas ou causais" (FOUCAULT, 1988, p. 27). Deve-se nem tanto julgá-la, mas incluí-la em sistemas de utilidade, regulá-la, administrá-la, fazer uma gestão da droga pelo poder público, como forma de otimizar e ordenar as forças coletivas e individuais que formam o Estado, e a República como forma de governo.

Sobre esse tema, Habermas faz uma interessante análise da mudança da estrutura discursiva e a ascenção de uma nova esfera pública, a partir do desenvolvimento do capitalismo. Tal esfera não mais se dá como antes, na corte feudal, ao redor do rei, mas passa a tratar dos interesses privados da classe dominante ascendente (HABERMAS, 1984). Nos salões dos charmosos cafés parisienses, eminentes burgueses reuniam-se para ler os jornais, ainda de circulação restrita, e debater dificuldades econômicas e gostos políticos; é da publicização das questões particulares que se trata a nova esfera, quando tais temas tornam-se dignos de fazer parte do debate público. É nesta época que Montesquieu escreve $O$ Espírito das Leis (1748), obra que inaugura a lista de tarefas do novo Estado Burguês, dentro do movimento filosófico e cultural não à toa auto-denominado Iluminismo. É preciso que os problemas privados da burguesia comecem a ser vistos não mais como "coisas da vida", mas como assuntos dignos de serem levados à praça púbica e discutidos. Porém, a ascenção da esfera pública não se explica objetivamente pela sua materialidade, mas sim pela nova posição em que o objeto é colocado, a importância que adquire, sua "invenção" discursiva, não necessariamente baseada em fatos. A agenda pública da sociedade passa a ser o que a mídia, que representa a classe dominante, considera importante (como bem exemplifica contemporaneamente o slogan do tradicional jornal The New York Times: "All the news that is fit to print"’3). Nesse novo e interessado interesse público, assim como com relação ao sexo, é

${ }^{3}$ Foi Carlos Eduardo Rebello quem reparou no slogan e o trouxe como exemplo para sala de aula. 
preciso instituir uma "polícia da droga" (ou uma "política da droga"), isto é, regulá-la por meio de discursos úteis e públicos (e não tanto pela proibição).

Um fato importante neste sentido é a ascenção (invenção) e estabelecimento do conceito de população como um assunto ou problema econômico e político. A constituição da ciência demográfica, os censos, as relações de equilíbrio ou desequilíbrio entre características da população e indicadores econômicos: mão-de-obra, População Economicamente Ativa, Produto Interno Bruto, riqueza. A idéia de que os governos lidam com uma população, que tem variáveis próprias, taxas de natalidade e mortalidade, expectativa de vida, fecundidade, pirâmide etária, condições de saúde, habitação, escolaridade, renda, aspectos quantificáveis e determinantes para o funcionamento ótimo do Estado.

No cerne desta questão política e econômica, diz o autor, está o sexo. E aí também se encontram as "drogas". Torna-se necessário gerir as diversas drogas de modo a potencializar e otimizar a produção do sistema; regulamentar as "drogas" consideradas benéficas para a saúde e vistoriar sua produção, distribuição e comercialização como remédios para a cura de doenças, gerir todo o sistema de saúde da população. Ocorre uma verdadeira "invasão farmacêutica", como chama Eduardo Viana Vargas, um boom da produção industrial de drogas em laboratório. Como apontou Foucault, esse crescimento é parte integrande de um processo mais geral de medicalização dos corpos e da vida (1982a apud VARGAS, 2008, p. 51). O Estado também deve regular a propaganda e o comércio das drogas toleradas, aquelas consideradas "culturais" e normais dentro de padrões determinados, como o tabaco e o álcool (cujo uso poderia ser considerado como uma válvula de escape para a população trabalhadora durante os momentos de folga, talvez evitando insatisfações populares e revoltas); cumpre cruzar dados e analisar a taxa de usuários das mais diversas drogas lícitas ou ilícitas, contabilizar a "toxicomania" da população; verificar a maneira de obter sucesso em processos terapêuticos utilizando drogas como cura, ou tentando fazer com que se cesse de utilizá-las, tratando seu uso como doença (de toda forma otimizando a saúde da população); avaliar a proibição ou a legalização de tal ou qual tipo de droga específica e suas consequencias; gerir o aparato repressivo judicial e policial, e o sistema penitenciário. De fato, a divisão moral que se estabelece entre as drogas de uso lícito e de uso ilícito ocorre principalmente a partir da década de 1940, durante a "invasão farmacêutica", quando explode a produção e uso de fármacos medicamentosos ao mesmo tempo em que se penaliza o uso das demais drogas (VARGAS, 2008, p.55). O uso de droga, assim como a sexualidade, é tomado ao mesmo 
tempo como objeto de análise e alvo de intervenção pelo poder público. Forma-se uma cadeia de saberes sobre o tema. O discurso oficial tenta fazer do comportamento sobre drogas uma conduta econômica e política deliberada. Entre o Estado e o indivíduo o uso de "drogas" se torna uma disputa pública, onde uma rede de discursos e saberes se encontram.

Semelhante processo ocorre com relação ao sexo das crianças, assim como a relação entre crianças e "drogas". Muito se fala sobre o assunto, mas de diferentes formas, por novos locutores, e para obter novos efeitos; mesmo o silêncio sobre o tema é um discurso bem definido e funcional. Que falas são autorizadas, e proferidas por quem? Nos colégios, as autoridades se colocam num estado de vigilância permanente. O discurso interno da instituição se organiza a partir do perigo da sedução das drogas sobre os jovens, que passa a ser um problema público. As crianças são consideradas vulneráveis, sem capacidade de discernimento acerca de sua conduta, suscetíveis à atração do desconhecido. Os alunos são ensinados sobre os perigos das drogas. Todo e qualquer tipo de "droga" é banida por princípio das dependências da instituição - mesmo que as prateleiras de sua enfermaria estejam repletas de drogas vendidas nas drogarias. Mesmo o álcool e o tabaco, substâncias regulamentadas, são terminantemente proibidas para os menores de idade. Campanhas de conscientização voltadas para a juventude são veiculadas nos jornais, rádio e televisão: “diga não às drogas". O uso de "drogas" por crianças e adolescentes passa a ser tema importante e em volta dele diversos dispositivos institucionais e estratégias discursivas se colocam.

A medicina, a partir do século XIX, entra decisivamente como campo de saber e poder gerando discursos sobre a sexualidade e sobre o uso de "drogas". Com relação ao sexo, toda uma gama de classificações de doenças e "perversões" são elaboradas a partir do sexo patológico; já as drogas são classificadas, agrupadas, catalogadas de acordo com critérios diversos, tipificadas, passam por estudos científicos que determinam suas consequencias, efeitos, interações medicamentosas, sequelas, e algumas enfim são consideradas administráveis em determinadas condições específicas estabelecidas pelo médico, transformadas em remédio, e estimuladas; às outras, toda uma noção de dependência, de drogadicção, seja em sua natureza química ou psicológica, atribui ao uso do tóxico seu caráter negativo, antinatural, antifuncional, patológico. Na medicina ocidental reina o funcionalismo, onde o corpo humano é considerado em equilíbrio no seu estado natural, com cada órgão exercendo sua função dentro do organismo, cuja estabilidade é apenas quebrada com a entrada de um agente externo que desorganiza, adoenta, patologiza, causa um problema que 
deve-se remediar para o retorno ao equilíbrio, à saúde. Famílias recorrem a psicólogos e psiquiatras para curar os desvios toxicológicos e sexuais dos filhos adolescentes. Clínicas para dependentes químicos combatem a "síndrome de abstinência" e trabalham na desintoxicação dos pacientes. As propagandas de cigarro e álcool estampam avisos sobre os perigos da utilização repetida das substâncias encontradas nesses produtos, cujos produtores devem, como contrapartida, fazer campanhas de conscientização ou apoio a instituições de tratamento a usuários abusivos. É pena prevista para o usuário de "droga" ilegal considerado dependente químico o tratamento compulsório em clínicas médicas. $\mathrm{O}$ dependente é tido como doente, incapaz de tomar decisões racionalmente, quase como um louco. O discurso médico é um dos focos preponderantes que atuam politicamente sobre as "drogas" e o uso de "drogas".

Similarmente, a justiça penal ocupa-se profundamente do uso de "drogas". Enquanto sobre o sexo limitou-se progressivamente a caçar os pequenos atentados ao pudor e a prostituição, com relação às "drogas" observa-se uma preocupação legal crescente com o uso das "drogas" proibidas. A própria percepção de um "problema das drogas" é relativamente recente. Ao longo do século XX, praticamente a maior parte dos países do mundo implementaram políticas repressivas ao uso de certas drogas (VARGAS, 2008, p. 54). No Brasil, qualquer relação mínima é criminalizada por "quem adquirir, guardar, tiver em depósito, transportar ou trouxer consigo, para consumo pessoal, drogas sem autorização ou em desacordo com determinação legal ou regulamentar (...)" (Artigo 28 da Lei de drogas brasileira, 2006). As penas são cada vez mais endurecidas para a produção e comercialização, o tráfico de drogas tornou-se crime inafiançável, onde o acusado não pode responder em liberdade. Em termos de representações, o traficante torna-se um dos maiores inimigos públicos, um vilão destruidor de lares, agente malicioso aliciador de jovens, carrasco que indica o caminho da perdição para inocentes filhos de famílias dignas. O jovem usuário é criminalizado em sua transgressão, considerado subversivo, sabotador, economicamente culpado pela contribuição ao tráfico e pela violência. Boa parte da atividade policial militar volta-se para a vigilância da venda e uso de drogas em logradouros públicos, e boa parte da população carcerária tende a ser formada por “criminosos do tráfico" (BOITEUX, 2009).

Esses são alguns dos campos estabelecidos do poder nos quais atuam feixes de relações políticas em determinadas formas discursivas que produzem dispositivos de vigilância e técnicas de controle acerca do sexo, e da "droga": 


\begin{abstract}
"Todos esses controles sociais que se desenvolveram no final do século passado e filtram a sexualidade dos casais, dos pais e dos filhos, dos adolescentes perigosos e em perigo - tratando de proteger, separar e prevenir, assinalando perigos em toda parte, despertando as atenções, solicitando diagnósticos, acumulando relatórios, organizando terapêuticas; em torno do sexo eles irradiaram os discursos, intensificando a consciência de um perigo incessante que constitui, por sua vez, incitação a se falar dele" (FOUCAULT, 1988, p. 32).
\end{abstract}

As formas discursivas penetram nas camadas mais sutis do cotidiano, agindo sobre o comportamento individual ao tornar o sexo desviante e a "droga" proibida objetos, além de uma reprovação moral, de uma repressão policial, uma ação judicial, uma intervenção médica, um estudo científico, um relatório jurídico, um censo demográfico, uma elaboração teórica.

\title{
Incorporação dos desvios: multiplicação dos prazeres e adicções
}

Desde a ruptura da passagem da idade clássica para a idade moderna o sexo provocou um erotismo discursivo generalizado, gerando um saber, que se multiplicou exatamente onde o poder se colocava, e como meio para seu exercício. Essa espécie de mudança de paradigma, como chamaria Kuhn no campo da ciência (2003), ocorreu em período fundamental para entender o contexto contemporâneo das sociedades ocidentais modernas, quando diferentes processos como o movimento Iluminista, a Revolução Industrial, o Êxodo Rural e Urbanismo, as Revoluções Burguesas, deram forma a profundas mudanças culturais, morais, filosóficas, econômicas, sociais e políticas, formando as novas bases da atual modernidade. Como consequencia dessa descontinuidade histórica dos sistemas de pensamento, com a inédita e positiva vontade de saber, a "droga" e seu uso também passaram a provocar uma espécie de "exotismo" discursivo generalizado. Ao indivíduo, nova categoria preponderante nas sociedades modernas (VELHO, 2004), se lhe impõe que tenha um discurso de confissão consciente e particular, seja ele "estabelecido" ou outsider (ELIAS, 2000; BECKER, 2009); de outro lado, as formas discursivas de ordem moral, religiosa, econômica, pedagógica, médica, legal, tomam a conhecer, gerem, regulam, incitam e organizam o uso de "drogas", a partir de diferentes instituições. Essa configuração indica a multiplicidade dispersa de focos emissores de discursividades que tomam diferente formas.

Esses dispositivos poderiam servir para de fato manter oculta a "droga", evitar o seu uso insubordinado à lógica da produção e reprodução (acabar com o uso por mero prazer, potencializar as drogas para a saúde), fornecer um uso economicamente útil e politicamente conservador da droga, já que definem uma norma de seu uso; entretanto, ao definirem a 
norma, caracterizam imediatamente todos os desvios possíves. Há uma multiplicação das formas de adicção, uma dispersão dos tipos de tóxicos e de dependências, um reforço de seus usos abusivos, a invenção de patologias e heterogeneidades toxicômanas.

Houve, fica claro, um movimento ao ascetismo, a valorização do "estar limpo", do não-uso de drogas. Concomitantemente, determinadas drogas se estabelecem como normais. Vargas aponta a emergência de um novo grupo de alimentos de luxo na Europa a partir do século XVII, os chamados "alimentos-droga": o café, o chá, o chocolate, o açúcar, o tabaco e as bebidas alcoólicas (2008, p. 47) Esses produtos moveram o mercado internacional da época e determinaram o desenvolvimento econômico e social de muitos países ao redor do mundo, como o Brasil. Atualmente, está estabelecido e valorizado culturalmente o cafézinho pela manhã e nos intervalos de trabalho, redobrando a disposição; o cigarro, símbolo de distinção, dotado de glamour, coisa chique usada por famosos do cinema (apesar de um movimento anti-tabagista forte ter surgido nas últimas décadas, mas esse é outro lado do assunto); a taça de vinho durante a refeição, atestada pelos cardiologistas mais renomados, a cervejinha após o trabalho, os drinks no cocktail, ou até mesmo a boa e velha pinga nas noite de festa. A pílula para acabar com a mínima dor de cabeça, atenuar a depresão, garantir a potência sexual ou fazer emagrecer: os remédios que trazem "qualidade de vida" (AZIZE, 2002).

O cidadão comum, com suas drogas regulares e normatizadas, não precisa se preocupar, tem direito à discrição. Todo o foco será dado à toxicomania dos subversivos, dos jovens em descaminho, dos viciados doentes, dos loucos e dos criminosos. Todos os desviantes agora devem tomar a palavra e confessar aquilo que são, escutados e condenados pela discursividade. O uso normal de droga passa a ser definido a partir do negativo do que são os usos abusivos. Frente a outras formas menos condenadas como a embriaguez planejada ou eventual, afigura-se um mundo da drogadição essencial que, antes de infringir a lei moral ou legal, fere uma lei natural anterior. Surge toda uma espécie de seres inferiores que se escondem pelos becos, muitas vezes perseguidos pela lei: doentes, delinquentes, vagabundos, desocupados; encerrados em penitenciárias ou casas de tratamento, fadados ao mal do vício e do delito. Crianças espertas demais, jovens precoces, fumaças ambíguas, elementos duvidosos e atitudes suspeitas habitam as diretrizes da disciplina, das viaturas policiais, das casas de correção e de saúde, das prisões, dos tribunais (FOUCAULT, 1988).

Assim como com relação ao sexo, a força da intervenção do discurso religioso sobre os usos das "drogas" foi perdendo um pouco de sua eficácia, cedendo paulatinamente espaço 
para a ciência da medicina asceder aos prazeres do indivíduo, determinando uma patologia orgânica, funcional ou mental, originada nos usos abusivos de "drogas" prejudiciais, categorizando as formas de dependência química e psicológica. A nomeação de toda a gama de tóxicos e usos nocivos ao organismo saudável tem menos como função a sua simples proibição. O discurso em torno da "prevenção" paradoxalmente apóia-se, em grande medida, em prazeres sutilmente sugeridos, exatamente a partir de sua constituição como algo proibido, como um segredo. Sugere implicitamente uma obrigação de ter que esconder tais usos, para que só então possam ser descobertos, através dos dispositivos de vigilância incitados por médicos, psicólogos, pedagogos e especialistas, instalados em instância primária no ambiente familiar. Define-se um regime médico dos usos de substâncias sobre o corpo. Organizam-se sobre o indivíduo linhas de penetração infinitas onde o poder avança multiplicando suas articulações e seus efeitos (FOUCAULT, 1988, p. 43).

Depois, esta caça aos usos não valorizados provoca a incorporação dos desvios e nova especificação do indivíduo. Tal identificação dada nos corpos e por eles sentida vale tanto para o sexo quanto para o uso de "drogas". "O homossesxual", como diz Foucault, torna-se um personagem, com um passado, uma infância, um caráter, um conjunto de acontecimentos de uma existência individual concebida como um trajetória orientada, linear e unidirecional, com um "sentido", enfim, uma história de vida (BOURDIEU, 1996), uma carreira desviante (BECKER, 2009). O mesmo vale para o "drogado":

\footnotetext{
"Nada daquilo que ele é, no fim das contas, escapa à sua sexualidade. Ela está presente nele todo: subjacente a todas as suas condutas, já que ela é o princípio insidioso e infinitamente ativo das mesmas; inscrita sem pudor na sua face e no seu corpo já que é um segredo que se trai sempre. É-lhe consubstancial, não tanto como pecado habitual porém como natureza singular" (FOUCAULT, 1988, p. 43).
}

A homossexualidade surge como uma figura da sexualidade quando a velha prática da sodomia na Grécia Antiga é transcendida a uma androgenia anterior, a um caráter concernente à natureza do ser, enquanto espécie (FOUCAULT, 1988, p. 44); de forma semelhante, a drogadição surge como categoria acerca do uso de "drogas" quando os divertidos personagens das festas em homenagem a Dionísio, o deus do vinho (ou Baco, na reedição romana), dão lugar ao alcóolatra contemporâneo.

“A mecânica do poder que ardorosamente persegue todo esse despropósito só
pretende suprimí-lo atribuindo-lhe uma realidade analítica, visível e permanente:
encrava-os nos corpor, introdu-lo nas condutas, torna-o princípio de classificação e 
de inteligibilidade e o constitui em razão de ser e ordem natural da desordem. Exclusão dessas milhares de sexualidades aberrantes? Não, especificação, distribuição regional de cada uma delas. Trata-se, através de sua disseminação, de semeá-las no real e de incorporá-las aos indivíduos" (FOUCAULT, 1988, p. 44).

Essa nova forma de poder, por se deitar sobre os corpos, exige aproximações, presenças, exames, observações do olhar curioso e interessado, um intercâmbio de discursos através de interrogatórios e confissões, um jogo de sensações que leva a uma espécie de sensualização do poder. Todos os saberes e os discursos médico, psiquiátrico, legal, pedagógico, familiar, funcionam como mecanismos de dupla-incitação: prazer e poder. Prazer de exercer o poder, controlar, vigiar; e prazer em escapar a esse poder, transgredir; poder que é contaminado pelo prazer que está caçando, e poder que se afirma no prazer de mostrar-se; como confronto e reforço recíprocos, nas perpétuas espirais de poder e prazer (FOUCAULT, 1988, p. 45).

Assim sendo, a sociedade moderna tratou de organizar e multiplicar sexualidades diversas nos indivíduos, assim como diferentes usos de "drogas", por via de uma "busca" de prazeres - no duplo sentido de desejados e perseguidos (FOUCAULT, 1988, p. 46). No seio da família, os hábitos arraigados, os olhares desconfiados, as portas trancadas, as caixas escondidas, os fundos de gaveta, as buscas de vestígios, os cheiros suspeitos, a atenção aos hábitos e amizades, os métodos de vigilância, os medos, formam uma rede complexa, saturada de usos ilegítimos de "drogas" múltiplas e mutáveis. Essa distribuição do jogo de poderes e prazeres se dá também nas instituições escolares e psiquiátricas. O tipo de poder que se passa a exercer sobre o corpo e o sexo não delimita a sexualidade, ao contrário, provoca suas diversas formas. Do mesmo modo, o poder que se passa a exercer sobre o corpo do indivíduo, e a introdução de substâncias neste corpo, não marca fronteiras para o uso da "droga"; antes, provoca suas diversas formas, como maneira de especificação dos indivíduos, atraídas pelo poder e prazer que se reforçam através de dispositivos de saturação. Há uma explosão dos usos de "droga", através de dispositivos de poder que se apóiam localmente em proibições mas que sustentam a multiplicação de prazeres específicos em sexualidades e toxicomanias desreguladas.

\section{Considerações finais}


Este trabalho pretendeu ser um exercício teórico de adaptação dos argumentos de Foucault sobre a sexualidade, desta feita aplicados à "droga" e seus usos. A hipótese subjacente é de que assim como com relação ao sexo, houve uma multiplicação de discursos e saberes sobre as "drogas", em regiões estabelecidas do poder, e um incitamento à sua formulação nas subjetividades individuais.

Houve certa dificuldade em utilizar textualmente o conceito de droga da mesma forma que Foucault usa o de sexualidade, pois é como se o próprio termo fosse já repleto de intenções, e de fato o é; os discursos poderosos parecem enfatizar o termo como tratando-se naturalmente das drogas ilícitas, tomando um sentido em si já estigmatizante, centralizando neste nome toda uma significância determinada, enquanto "sexualidade", parece-me soar mais geral, talvez menos comprometido.

De toda forma, afora as especificidades, creio ser necessário para um debate sobre a "questão das drogas" o argumento de que a "droga" é objeto de gestão de um saber e um poder institucionalizados, na medida em que se inscrevem nos corpos como esferas de liberdade individual que por determinações sociais e históricas foram sendo construídas discursivamente, e paulatinamente domesticadas.

\section{Referências Bibliográficas:}

AZIZE, Rogerio Lopes. A química da qualidade de vida: um olhar antropológico sobre uso de medicamentos e saúde em classes médias urbanas brasileiras. 2002. 118f. Dissertação (Mestrado) - Departamento de Antropologia, Universidade Federal de Santa Catarina, Snata Catarina, 2002.

BECKER, Howard S. Outsiders: estudos de sociologia do desvio. Rio de Janeiro: Jorge Zahar, 2009.

BOITEUX, Luciana. "Tráfico e Constituição: um estudo sobre a atuação da justiça criminal do Rio de Janeiro e de Brasília no crime de tráfico de drogas”. In: Revista Jurídica volume 11, n. 94, 2009.

BOURDIEU, Pierre. "A Ilusão Biográfica”. In: FERREIRA, Marieta de M.; AMADO, Janaína. Usos e Abusos da História Oral. Rio de Janeiro: FGV, 1996. 
ELIAS, Norbert; SCOTSON, John. Os Estabelecidos e os outsiders: Sociologia das relações de poder a partir de uma pequena comunidade. Rio de Janeiro: Jorge Zahar Editor, 2000.

FOUCAULT, Michel. História da Sexualidade I: A Vontade de Saber. 11. a ed. Rio de Janeiro: Graal, 1988.

As Palavra e as Coisas: Uma Arqueologia das Ciências Humanas. São Paulo: Martin Fontes, 2000a.

. A Arqueologia do Saber. Rio de Janeiro: Forense, 2000b.

GUARINELLO, Norberto Luiz. "O vinho: uma droga mediterrânea". In: LABATE, Beatriz Caiuby; GOULART, Sandra; FIORE, Maurício; MACRAE, Edward; CARNEIRO, Henrique (orgs.). Drogas e Cultura: novas perspectivas. Salvador: EdUFBA, 2008. Pg. 189-198.

HABERMAS, J. Mudança Estrutural da Esfera Pública. Rio de Janeiro: Tempo Brasileiro, 1984.

KUHN, Thomas. A estrutura das revoluções científicas. 7. ${ }^{\text {a }}$ ed. São Paulo: Perspectiva, 2003.

PRESIDÊNCIA da República. Lei $\mathrm{n}^{\circ}$ 11.343. Brasília, 2006. Disponível em $<$ http://www.planalto.gov.br/ccivil_03/_ato2004-2006/2006/lei/111343.htm>. Data de acesso 11 de Julho de 2012.

VARGAS, Eduardo Viana. "Fármacos e outros objetos sócio-técnicos: notas para uma genealogia das drogas". In: LABATE, Beatriz Caiuby; GOULART, Sandra; FIORE, Maurício; MACRAE, Edward; CARNEIRO, Henrique (orgs.). Drogas e Cultura: novas perspectivas. Salvador: EdUFBA, 2008. Pg. 41-63.

VELHO, Gilberto. "Projeto, Emoção e Orientação em Sociedades Complexas". In: . Individualismo e Cultura. Rio de Janeiro: Jorge Zahar Editor, 7ª Ed., 2004 [1981] 


\title{
FOUCAULT AND DISCOURSES ABOUT "DRUGS": FROM DEFINITION OF THE OBJECT TO THE INCORPORATION OF DEVIANCES.
}

\begin{abstract}
This article is a reflexive exercise on the use of drugs currently, using the theory framework developed by Foucault in his analysis on sexuality. The underlying hypothesis is that it is possible to identify in modern societies a process in which "drugs" are put into speech, defining them as an object of knowledge and to be controlled. Therefore this text hopes to analyze the different discursive formations about "drugs" and their depictions in the established fields of power, culminating in a reflection on the consequences of such process in one's individual formulation of the use of "drugs" and a subjective incorporation of the deviances.
\end{abstract}

KEYWORDS: Drugs, Deviance, Subjectivity 